\title{
Stability Analysis of Single Layer Latticed Shell Structure
}

\author{
Guo Weigang, a \\ ${ }^{1}$ School of Civil Engineering and Transportation, South China University of Technology, \\ Guangzhou, 510006, China. \\ aguoweigang7@126.com
}

Keywords: Kiewitt-6, stability, initial geometric defect, material nonlinearity

Abstract: The Kiewitt-6 single layer latticed shell structure is selected as the research object. The latticed shell's rapid modeling and global stability analysis are carried out in the form of command flow by using the finite element analysis method. The finite element software ANSYS is used to analyze the Kiewitt-6 single layer latticed shell, and the initial defect of the structure and the material nonlinearity are considered. The loaddisplacement curves of latticed shells with initial defects and double nonlinearity are analyzed. It is concluded that the stiffness and bearing capacity of latticed shells will be weakened if initial defects and double nonlinearity are taken into account.

\section{Introduction}

With the development of economy, engineers are paying more and more attention to large-span spatial structures. In the Technical Specification for Space Frame Structures (JGJ7-2010) [1], it is stipulated that the maximum span of single-layer spherical reticulated shell should not be larger than $60 \mathrm{~m}$, but there are many single-layer spherical latticed shells with span of more than $60 \mathrm{~m}$ in practical projects. Therefore, there are more and more studies on large-span single-layer spherical reticulated shells, and the stability of latticed shell is the most important research topic. [2-5]

\section{Structure Geometry}

The finite element analysis model of this paper is a Kiewitt-6 single-layer spherical latticed shell. The span of the latticed shell is $70 \mathrm{~m}$, the vector height is $14 \mathrm{~m}$, the vector height ratio is $1 / 5$, the main bar and the weft bar are $\Phi 159 \times 6$, the inclined rod is $\Phi 159 \times 6$, the latticed shell has 14 rings. The supporting condition of the surrounding nodes is hinged. The form of load is equivalent node load. Geometric nonlinearity and material nonlinearity of latticed shell are considered in the process of analysis. In this paper, the static stability of Kiewett- 6 single-layer spherical latticed shell will be deeply analyzed.

\section{Material Selection, Unit Division and the Load}

The steel used for the latticed shell steel is Q345. The yield strength is 345MPa. The elastic modulus is $2.06 \times 10^{5} \mathrm{MPa}$. The Poisson's ratio of material is 0.3 , and the density is $7800 \mathrm{~kg} / \mathrm{m}^{3}$. An ideal elastoplastic constitutive model is used in the steel constitutive model. The general finite 
element analysis software ANSYS is used to calculate the latticed shell, and the APDL language is written for modeling and analysis. The element type is beam188 model.

Considering the weight of structure, the dead load is $0.5 \mathrm{KN} / \mathrm{m}^{2}$, the live load is $0.5 \mathrm{KN} / \mathrm{m}^{2}$, the arrangement of live load is divided into two types: full span load and half span. In the following discussion, the full span load will represent the full span dead load and live load average distribution, and the half span load will represent the full span dead load and half span live load average distribution. The joint reaction force of the structure under each working condition is obtained by applying the surface load, and then applied to the node of the structure as the load of the model.

\section{Analysis of Several Factors Affecting the Stability of Latticed Shell}

There are many factors affecting the stability of latticed shells. In this paper, the following conditions are considered: initial defect, load arrangement, only considering geometric nonlinearity, and considering double nonlinearity (geometric and material nonlinearity). The main research ideas:

The effect of different initial defect values on the ultimate bearing capacity of latticed shell is studied. In this paper, the effects of different initial defect values on the stability of latticed shell with full span and half span load are analyzed. Five comparative models (A1 to A5) are established to study the effect of different initial defect values on ultimate bearing capacity of latticed shell under full span load. These five models take into account the initial defect values as a span of $1 / 200$, $1 / 250,1 / 300,1 / 400,1 / 500$. Considering the nonlinearity of geometry and material. The bar is divided into one unit. The effect of different initial defects on the ultimate bearing capacity of latticed shell was obtained by using the uniform defect mode method. In the same way, five comparative models (B1 to B5, see Table 1 below) under half span load are analyzed by the same methods. Details are given in Table 1.

The influence of considering double nonlinearity and only considering geometric nonlinearity on the bearing capacity of latticed shells are studied. In order to obtain the influence of nonlinear on the bearing capacity of latticed shell under different load arrangement modes, four factors, including full span load, half span load, only geometric nonlinearity and double nonlinearity, are considered at the same time. Four comparative models (C1 to C4, given in Table 1 below) are established to study the effect. The comparison of full span load and half span load under different initial defect values is considered.

Table 1 Variable parameters of finite element model

\begin{tabular}{cccccccccc}
\hline Model & $\begin{array}{c}\text { Initial } \\
\text { defect }\end{array}$ & nonlinearity & $\begin{array}{c}\text { full } \\
\text { span }\end{array}$ & $\begin{array}{c}\text { half } \\
\text { span }\end{array}$ & Model & $\begin{array}{c}\text { Initial } \\
\text { defect }\end{array}$ & nonlinearity & $\begin{array}{c}\text { full } \\
\text { span }\end{array}$ & $\begin{array}{c}\text { half } \\
\text { span }\end{array}$ \\
\hline A1 & $1 / 200$ & double & $\sqrt{ }$ & $\times$ & B3 & $1 / 300$ & double & $\times$ & $\sqrt{ }$ \\
A2 & $1 / 250$ & double & $\sqrt{ }$ & $\times$ & B4 & $1 / 400$ & double & $\times$ & $\sqrt{ }$ \\
A3 & $1 / 300$ & double & $\sqrt{ }$ & $\times$ & B5 & $1 / 500$ & double & $\times$ & $\sqrt{ }$ \\
A4 & $1 / 400$ & double & $\sqrt{ }$ & $\times$ & C1 & $1 / 300$ & double & $\sqrt{ }$ & $\times$ \\
A5 & $1 / 500$ & double & $\sqrt{ }$ & $\times$ & C2 & $1 / 300$ & geometrical & $\sqrt{ }$ & $\times$ \\
B1 & $1 / 200$ & double & $\times$ & $\sqrt{ }$ & C3 & $1 / 300$ & double & $\times$ & $\sqrt{ }$ \\
B2 & $1 / 250$ & double & $\times$ & $\sqrt{ }$ & C4 & $1 / 300$ & geometrical & $\times$ & $\sqrt{ }$ \\
\hline
\end{tabular}

\section{Finite Element Analysis Results}

\subsection{Buckling analysis of eigenvalues of latticed shell.}

Taking the finite element models A4 and B4 as examples, the eigenvalue buckling analysis is 
carried out. The first 10 order buckling factors of the structure under the full span load are shown in Table 2, and the first three buckling modes are shown in Fig. 1 to Fig. 3. The analytical results under half span load are shown in Table 2, and Fig. 4 to Fig. 6.

Table 2 The buckling factors of structures under full span load and half span load

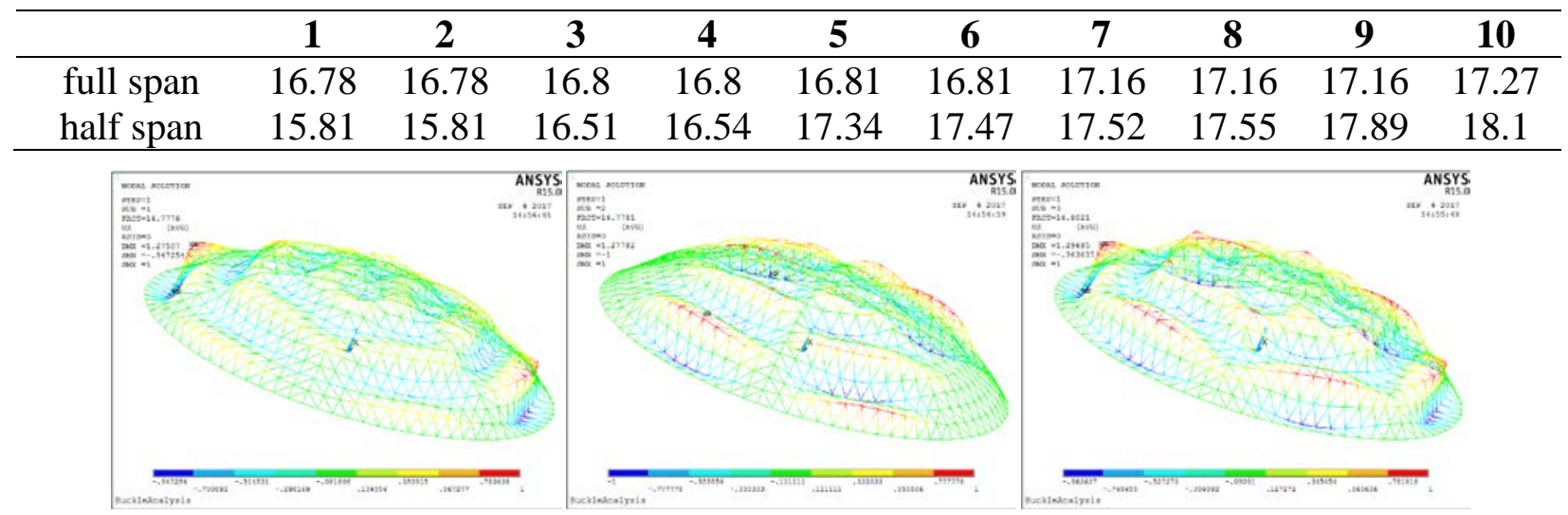

Fig. 1 first order

Fig. 2 second order

Fig. 3 third order

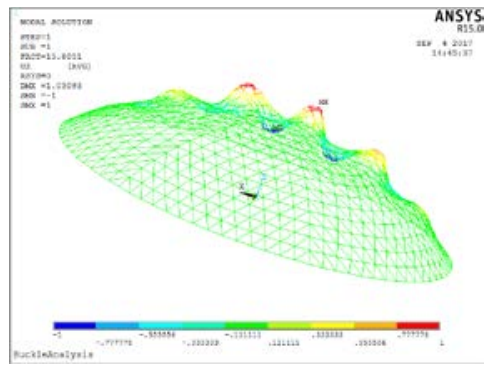

Fig. 4 first order

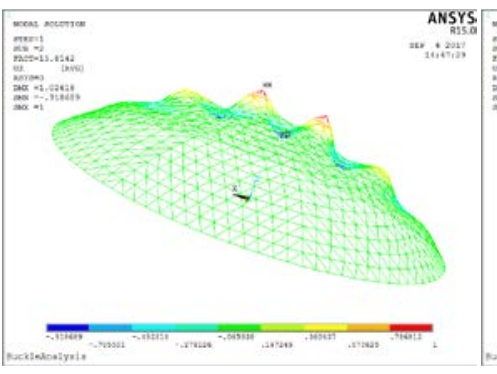

Fig. 5 second order

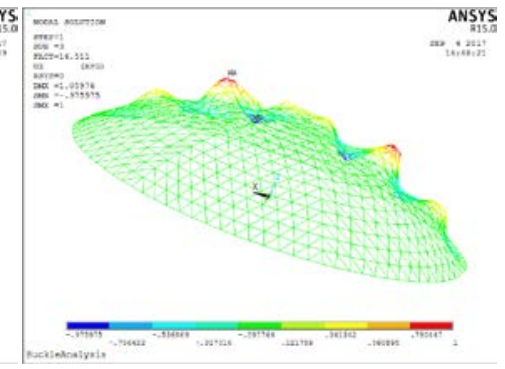

Fig. 6 third order

It can be seen from Table 2 that the buckling factor of latticed shells under half span load is smaller than that under full span load. It is shown that half span load is more disadvantageous, which is consistent with the conclusion of relevant papers. Related studies show that the ultimate bearing capacity of the latticed shell under unsymmetrical load will be reduced, but the reduction ratio is smaller, about $18 \%$ to $22 \%$. From Figs. 1 to 3, it can be seen that the buckling modes of latticed shells are mainly upper convex and subsidence under the full span load, and the upper convex and subsidence alternately appear. However, from Figs. 4 to 6, it can be seen that the buckling modes of latticed shells under half-span load are mainly the upper convex and the subsidence of the part with no live load.

\subsection{Effect of initial defect on ultimate bearing capacity of latticed shell.}

The calculation results of the finite element model A1 to A5 are shown in Fig. 7 and B1 to B5 are shown in Fig. 8. It can be seen from these two figs that the ultimate load decreases with the increase of the initial defect value. When the initial defect value varies from $1 / 500$ to $1 / 300$, the difference of ultimate load is more uniform. However, from $1 / 300$ to $1 / 200$, the ultimate load varies considerably. This is shown that the latticed shell will be more vulnerable to instability if there are large errors in the installation process and the initial defects are larger.

In addition, with the increase of initial defect, the slope of the first half of the load-displacement curve of the latticed shell becomes smaller, that is, the stiffness of the latticed shell becomes smaller. With the increase of initial defect, the ultimate bearing capacity of latticed shell decreases gradually, 
and the stiffness of latticed shell decreases faster and faster.

From the comparison of Fig. 7, Fig. 8 and Table 3, it can be found that the ultimate bearing capacity of half-span load is smaller than that of full-span load. Therefore, it is very important for the design of engineering projects to consider the initial defect of the latticed shell and select the appropriate initial defect value.

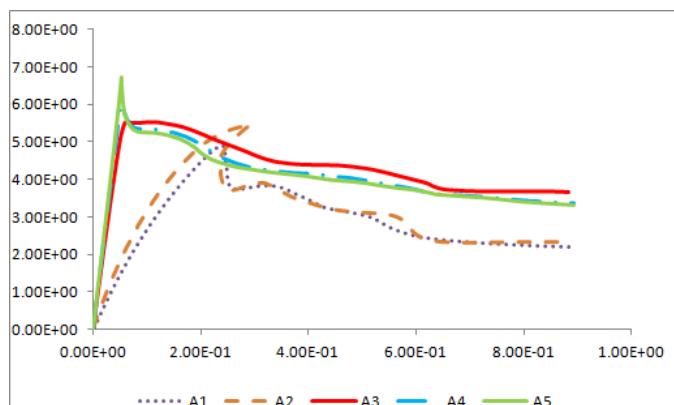

$\cdots \mathrm{A}_{1}-\mathrm{A}_{2}-\mathrm{A}_{3}-\mathrm{A}_{4}-\mathrm{A}_{5}$

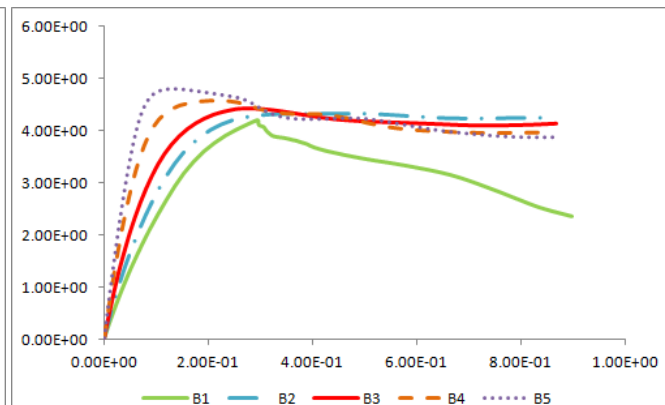

Fig. 7 load-displacement curves under full-span load Fig. 8 load-displacement curves under half-span load

Table 3 Ultimate bearing capacity of latticed shells considering different initial defects

\begin{tabular}{cccccc}
\hline Model & Initial defect value & Load factor & Model & Initial defect value & Load factor \\
\hline A1 & $1 / 200$ & 4.90 & B1 & $1 / 200$ & 4.19 \\
A2 & $1 / 250$ & 5.45 & B2 & $1 / 250$ & 4.33 \\
A3 & $1 / 300$ & 5.54 & B3 & $1 / 300$ & 4.42 \\
A4 & $1 / 400$ & 6.06 & B4 & $1 / 400$ & 4.57 \\
A5 & $1 / 500$ & 6.72 & B5 & $1 / 500$ & 4.80 \\
\hline
\end{tabular}

\subsection{Influence of load layout on ultimate bearing capacity of latticed shells.}

Only two load arrangement modes, full span load and half span load, are considered in this paper. The load-displacement curves of latticed shell subjected to full span and half span load under three different initial defects $(1 / 200,1 / 300,1 / 400)$ are investigated. The finite element models are A1, B1, A3, B3, A4, B4. The results are shown in Fig. 9 to Fig. 11.

From Fig. 9 to Fig. 11 and Table 3, it can be seen that the ultimate bearing capacity of half-span load is smaller than that of full-span load, but the difference of ultimate load between them is very small under various initial defects, which is within $5 \%$. It is also pointed out that unsymmetrical load has little effect on the ultimate load bearing capacity of latticed shell.

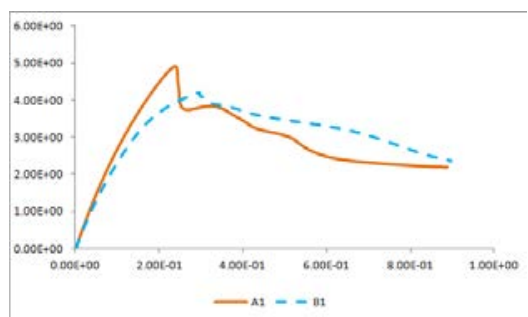

Fig. 9 1/200

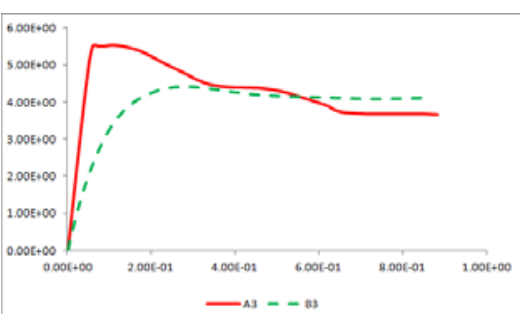

Fig. 10 1/300

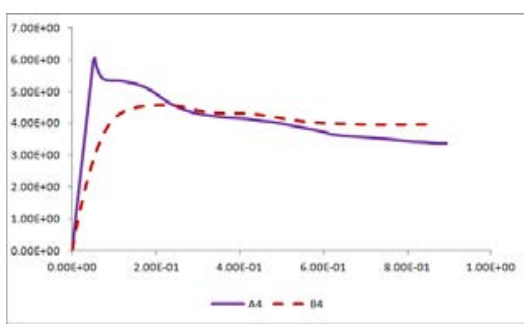

Fig. 11 1/400

\subsection{Effects of geometric nonlinearity only and double nonlinearity on ultimate bearing capacity of latticed shell.}

The effects of geometric nonlinearity only and double nonlinearity on the ultimate bearing capacity of latticed shells under full span load and half span load are calculated respectively. The 
latticed shell models are numbered C1, C2, C3, C4 (given in Table 1). The results of the analysis are shown in Fig. 12 and Fig. 13.

From Fig. 12 and Fig. 13, it can be seen that the ultimate bearing capacity of latticed shells will decrease after considering the material nonlinearity, and even obviously, whether it is full span load or half span load. Therefore, in engineering projects, when calculating the ultimate bearing capacity of this kind of latticed shell, it is necessary to consider both geometric and material nonlinearity, so that it can be more close to the actual stress situation of the latticed shell.

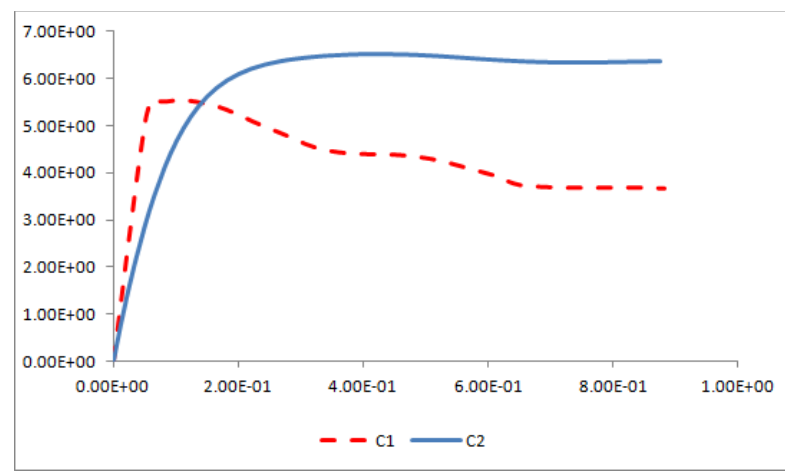

Fig. 12 full-span load

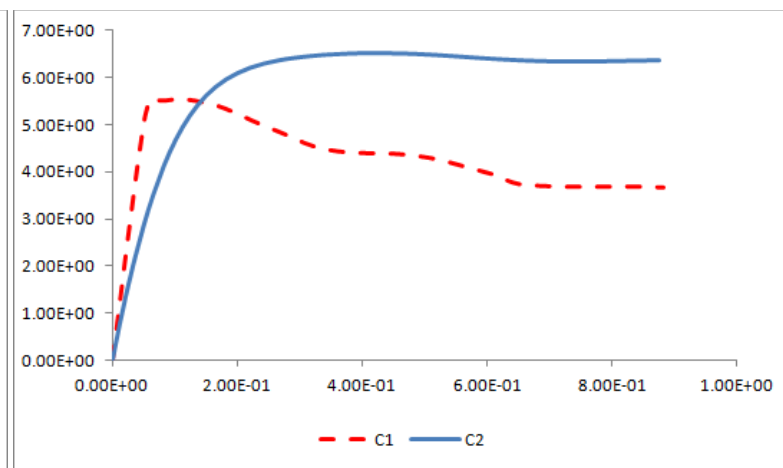

Fig. 13 half-span load

\section{Conclusion}

If the initial defect of the latticed shell are considered in analysis, the stiffness and ultimate bearing capacity of the latticed shell will be reduced to a certain extent. With the increase of initial defect, the stiffness of latticed shell decreases more and more quickly, and the ultimate bearing capacity of latticed shell decreases gradually.

In the stability analysis of latticed shells, the ultimate bearing capacity of half-span load is smaller than that of full-span load, but the difference between the two ultimate loads under the same initial defect is very small, basically within $5 \%$.

When only geometric nonlinearity is considered, the ultimate bearing capacity of latticed shell is larger, but the ultimate bearing capacity of latticed shell decreases obviously if considering material nonlinearity. Therefore, in engineering projects, when calculating the ultimate bearing capacity of this kind of latticed shell, it is necessary to consider both geometric and material nonlinearity, so that it can be more close to the actual stress situation of the latticed shell.

In the design, the initial defects of latticed shell structures should be reduced as much as possible, and the initial defects of latticed shell should be reasonably selected. In the Technical Specification for Space Frame Structures (JGJ7-2010), it is stated that the initial defect of single layer spherical latticed shell should not be greater than that of span 1/300.

\section{References}

[1] JGJ7-2010, Technical Specification for Space Frame Structures [S]. Beijing: China Architecture \& Building Press, 2010.

[2] Zhang Zexin. The nonlinear stability study on K6 single-layer spherical reticulated shell [D]. Xi'an: Xi'an University of Architecture and Technology, 2015.

[3] Lu Yan. Theoretical analysis and experimental research on collapse mechanism of large-span arched frame [D]. Tianjin: Tianjin University, 2012.

[4] Qinghua HAN, Yan LU, Baolin YU, etc. Ultimate Load Capacity and Reinforcement of Tubular N-joint, Transactions of Tianjin University, 2010, 16(1):1-5.

[5] Xiao Xiaoping. Nonlinear stability analysis of single-layer spherical lattice shell [D]. Changsha: Hunan University, 2011. 